\title{
Atherosclerosis-disease of old age or infancy?
}

\author{
C. I. LEVENE 1
}

From the Department of Pathology, University of Cambridge

I have divided this paper into five parts. I wish, firstly, to review the history of research into atheroma; secondly, to discuss briefly the major theories of its aetiology; and, thirdly, to discuss in more detail three particular aspects-mural thrombosis, mechanical factors, and medial weakness. Fourthly, I would like to tell you about some of our recent work, which will attempt to bring together certain of these factors into a theory of pathogenesis. This new work helps me to explain what seems to be the first visible morphological manifestation of atherosclerosis occurring at birth. It has already become a cliché to say that this disease is multifactorial-which $\mathrm{I}$, too, believe it to be. However, there will be, I hope, one virtue to this new look-which is that, if true, it may open up possibilities of retarding or even preventing the disease. Good science, one likes to think, must mean predictability and, one hopes, eventual prevention of a disease. In the fifth and final section we shall see whether what I have to say stands up to this test.

\section{History of atheroma research}

During the past 125 years more than a few studies have been made of atheroma. This body of work seems to fall into four phases. Perhaps this is the way all research happens. We, too, have our conservationists who, with deep feeling, defend our doctrines and our gods, and we also have our revolutionaries who feel perhaps that the gods have feet of clay. It seems absolutely fair in an age of Darwinism that revolutionaries too should be put to the test of the ducking stool. Observe then how history has treated these two types in the field of atheroma.

During the second half of the 19th century investigations were made by the morbid anatomists (Rokitansky, 1852; Virchow, 1856; Thoma, 1896; Marchand, 1904; Jores, 1903; and Adami, 1909). These were absolutely reasonable given that the necropsy and the microscope were then sceptre and orb, leading the field technologically. Anitschkow

${ }^{1}$ Member of the external scientific staff of the Medical Research Council.
(1913) discovered that feeding cholesterol to rabbits produced arterial lesions. This started a new phase of biochemical investigation into the disease, one which still continues.

In 1938 Winternitz and his colleagues, seemingly oblivious to the war to come, kept their eyes on the ball and published their classic monograph on the role of haemorrhage commonly present at the edges of atherosclerotic plaques in the aorta. They were followed by Duguid (1946) who meanwhile, being British, had had other affairs to attend to. It was then that he published his classic paper on the role of mural thrombosis in the pathogenesis of atherosclerosis. I would like to call this phase that of the 'experimental pathologists'. Since that time until the present the subject has opened up as new techniques and methods of communication have also opened up -and here I include Current Contents-so that research in the field has embraced many disciplines (or lack of disciplines) such as epidemiology, tissue culture of smooth muscle or endothelium, platelet studies, fibrinolysin investigations, the genetic approach, and, of course, the clinical approaches, both medical and surgical. It is, incidentally, still a mystery to me whether rapid communications have helped or hindered original research.

\section{Review of theories of atheroma}

I will now briefly review those theories of the pathogenesis of atheroma of which I am aware. Certainly I will have missed some. For this I apologise and blame my ignorance of the literature.

Firstly, we have Virchow's classical theory (1856) in which he incriminated intimal degeneration followed, as a secondary phenomenon, by fibrous intimal thickening. The emphasis, you will note, is on the intima. Secondly, Anitschkow (1913) demonstrated that feeding rabbits with cholesterol produced arterial lesions which, he claimed, resembled atheroma. Since then much energy and even more money have gone into testing this view, and testing continues to this day. I do not propose, nor am I equipped, to discuss this view in detail. Briefly, I 
feel sceptical that Anitschkow's model represents a valid one of the human condition. I have often thought that trying to produce atheroma by feeding fats to an animal because the atheromatous plaque contained fat was as naive as trying to produce a haematoma experimentally by feeding calcium or haemosiderin because old haematomas often contain calcium and haemosiderin. Anitschkow's logic was unable, naturally, to take account of the then little understood biochemical facts regarding lipids.

Thirdly, there are the mechanical views of pathogenesis. These take in a host of factors: (1) hypertension, including the increase in atheroma found in pulmonary hypertension and proximally to coarctation in the aorta; (2) gravity - the lower limbs commonly show severe atherosclerosis in the absence of clinical symptoms-probably the price we pay for being those Orwellian creatures-two legs, bad, very bad. We also require to consider (3) rheological factors such as turbulence; (4) anatomical factors such as tethering of vessels at branch sites; and (5) medial weakness, of which I hope to speak later. Meanwhile, may I remind you, fourthly, of Harrison's (1933) experiment in which he showed that if parts of the aorta were immobilised in vivo by plaques of calcium which had been produced by feeding excess vitamin $D$ the effects of hypercholesterolaemia subsequently could be seen only in the calcium-free areas-that is, those parts that could move with each pulsation and not in the zones which had been immobilised by the calcification. I shall deal later with the effect on a pulsating artery of the textural differences between a rigid fibrous plaque adherent to a pliant blood vessel wall which is in constant motion.

Fifthly, we come to the thrombogenic hypothesis. Of this, too, I shall say more. Sufficient now to say that it states that mural thrombi may become incorporated into the arterial wall and produce atherosclerosis with narrowing of the lumen. Vascularisation by capillaries of the intima occurs when a thrombus is organised via the media and via the intima. Winternitz et al. (1938) were the first to show that these capillaries, absent from the normal intima, are liable to haemorrhage-which they so commonly found at the edges of plaques. Geiringer (1951) showed that plaque thickness played a critical role in vascularisation. He blamed most of the, as he believed, secondary changes in the plaquefatty debris, calcification, haemorrhage-on accidents to these capillaries. Later Crawford and I, as his then research fellow, provided evidence to confirm this view (Crawford and Levene, 1952). I would go so far as to say that when intimal capillaries are present they signify a thrombus which is, or has been, organised into a plaque. Capillaries are not often easily seen, but if a vessel is fixed at diastolic pressure with formalin they become much more evident, and if plaques are sectioned longitudinally, as we did, it is seen that they may form large sinuses in contact with the main blood stream in the lumen.

Sixthly, there is the view that man is as old as his arteries-rather a pessimistic view no doubt containing large elements of truth, but not, I think, the complete truth.

Next, and seventh, Rinehart and Greenberg (1949) produced what they claimed to resemble human atheroma in monkeys by maintaining them for two and a half years on a vitamin B6-deficient diet. They came to believe that B6 deficiency is an important aetiological factor. I, too, believe this to be the case but, as I hope to show later, for different reasons. In the late 19th century, in the heyday of infectious diseases of childhood, and especially during the influenza pandemic at the end of the first world war, pathologists saw much paediatric pathology. Some believed that infection was a major cause of atherosclerosis. Preventive medicine has changed the clinical picture but of course infection still occurs, so it might be wise to keep an open mind as to the role of infection in atheroma.

Of recent years three new theories have been postulated. The Crawfords (Crawford and Crawford, 1967) have highlighted and investigated the finding that people living in areas supplied by soft water suffered more atherosclerosis than those living in hard water areas. This may turn out to be a formidable theory. Next, the Benditts (Benditt and Benditt, 1973) have provided evidence that atherosclerotic plaques in the aorta appear to be monoclonal on the basis of the type of lactate dehydrogenase isoenzyme present in the cells-the smooth muscle cells-which comprise the plaque or, indeed, the tumour. While appreciating that genetically this has interest and elegance, I cannot see how it helps to clarify the pathogenesis of the disease. But doubtless time will tell. Finally, Yudkin and Roddy (1964) incriminate sucrose as the major cause of atheroma. Here, too, I can express no view except that time again will doubtless tell.

\section{Review of three special factors}

I will now speak in detail of three conditions considered to be major factors in atherosclerosis. Two of them, mural thrombosis and the physical damage done by the pulsation movement at the base of a plaque, represent two major contributions that my former chief, Duguid, has made to the field in his $\mathbf{5 0}$ years of investigation into atheroma. The third factor, medial weakness, contains old and newer fragments of evidence. 
MURAL THROMBOSIS

Rokitansky (1852), a distinguished pathologist, put forward the view and the morphological evidence that encrustations from the blood contributed towards the thickening of atheromatous plaques in the aorta. Virchow (1856), the doyen of pathology, dismissed this view in rather more abrasive terms than we should ever dream of using now. In his paper he referred to Rokitansky as 'dieser gemeine Kerl'-'this damned fellow'. Perhaps Virchow really did link pathology with theology. Damnation, however, seems a high price to pay for putting forward a seemingly innocuous, unrevolutionary view. Apparently what Virchow could not accept was that a component which was under the endothelium could have come from the blood stream and then been covered by endothelium. But Duguid, in his latest monograph (1976), now refers to the endothelialisation of a mural thrombus as a principlehow times have changed!

Ziegler (1896-97) refers to 'organising fibrin thrombi' in atheromatous vessels. This, however, was all forgotten and was replaced by Anitschkow's work until Duguid's 1946 paper in which he, as many of us believe, firmly established that the organisation of mural thrombi in arteries was often the basis of the atheromatous plaque. He did not claim this to be a primary initiating event but to be a major contribution to plaque growth. It is worth knowing how this view came to be. While teaching a class at the Welsh National School of Medicine Duguid discussed the recanalisation of an occluding arterial thrombus. Some students could not find the double lumen in their sections, which had only a single lumen containing an atheromatous plaque. Duguid then had a marvellous flash of intuition. He realised that all sections in this class had come from a single block. He collected them all up, put them in order, and, from a careful study, concluded that an organised thrombus with time would come to resemble an atheromatous plaque. He reasoned that, conversely, a plaque could therefore originate from the organisation of a mural thrombus. Since then several workers have confirmed this view. Harrison (1948) injected fragments of fibrin into the pulmonary circulation of a rabbit and found that they later organised into what appeared to be intimal plaques in the pulmonary arteries. Heard (1949) observed organising thrombi in renal arteries; Magarey (1949) found them on the mitral valve, the so-called Lambl's excrescences; and Crawford and I (Crawford and Levene, 1952) confirmed and extended Duguid's findings in the aorta and in the coronary arteries.

I do not propose to go into the great deal of work which has been done in the last 15 years on platelets and on the fibrinolysin mechanism except perhaps to say how original and interesting I have always thought Mole's (1948) observation was when he asked himself whether the old aphorism propounded by Morgagni, that 'the blood of people who die a violent death never clots', really was true and showed that in fact their blood had already clotted but that the fibrin had subsequently lysed and so there was no fibrinogin left to clot. This was the beginning of the fibrinolysin story which opened up the possibility that among the causes of thrombosis one should consider a diminution in the degree of natural fibrinolytic activity which the aortic endothelium normally possesses.

\section{PLAQUE-PULSATION INTERACTION}

In his latest monograph Duguid (1976) has emphasised a factor not generally mentioned in the literature but which he considers to be extremely important. Briefly, it is that a fibrous intimal plaque, which is much more rigid than the vessel to which it adheres and which is pulsating regularly, is bound to create an unstable complex. The results eventually are often a tearing and splitting of the plaque at its base with resultant haemorrhage which may be seen in the fresh aorta, using Patterson's haemosiderin stain. In effect, he confirms Winternitz's findings but is offering what seems to be a thoughful mechanistic explanation for a common phenomenon which is happening in a mechanical system. I had not thought much about this until now, but I do think he has touched an important point here.

\section{MEDIAL WEAKNESS}

What is the evidence that the aorta or large arteries develop localised areas of medial thinning which may 'blow out', producing shallow aneurysms? It was the view of many of our great pathological forbears (Thoma, 1896; Adami, 1909; Faber, 1912; and Beitzke, 1928) that the primary lesion in atheroma of the aorta was a localised elastin weakness in the media. Duguid (1926) explained the focal nature of aortic atheroma as due to localised stresses that impaired elasticity and produced a reactive fibrous intimal overgrowth. The empirical fact is that medial thinning is common beneath the fairly large plaque. In 1953 Crawford and I showed that the commonly observed bulging of the plaque into the lumen was a post-mortem artefact (Crawford and Levene, 1953) and that fixation of the aorta with formalin in diastole resulted in a circular lumen, the plaque then actually bulging into the media, which appeared much thinner than normal (Fig. 1a, b). We thought that localised medial weakness existed but was difficult to demonstrate unless the vessels were fixed 


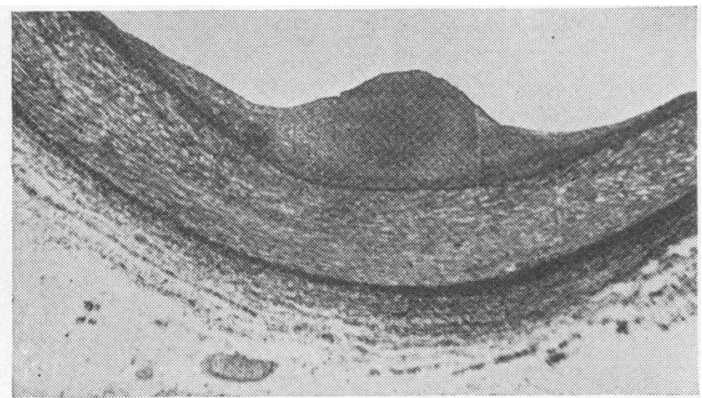

(a)

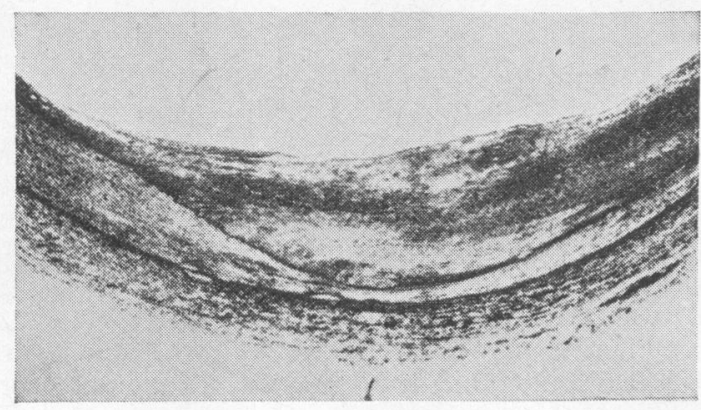

(b)

Fig. 1 (a) Atheromatous plaque in undistended external iliac artery. (haematoxylin and eosin $\times 14$ ). (b) Atheromatous plaque in distended external iliac artery. Note that intimal thickening lies in a medial hollow and does not project into the lumen.

(Haematoxylin and eosin $\times 12$ )

under pressure. The plaques, it was suggested, were the results of the filling-in of shallow aneurysms.

\section{Original work}

I would now like to describe some of my own work. In 1953 Crawford suggested to me that as a topic for an M.D. thesis I should examine the site in human coronary arteries where atheroma is most commonthe junction of the left anterior descending and circumflex coronary arteries-and that I should do this in younger subjects to reveal any structural changes that preceded plaque formation. I examined 98 hearts, spanning all age groups from prematurity to 80 years. The most striking finding was of focal lesions of the internal elastic lamina in the very young, including premature babies (Levene, 1956a). The lesions consisted of a localised splitting of the elastica with no overlying intimal thickening (Figs 2,3). This type of lesion was observed in 9 out of 15 full-term infants and in some early fibrous thickening appeared over the lesion (Figs 4, 5). In the 0-10-year group a gradation of increasing severity could be traced leading to an appearance in the older age groups indistinguishable from that of a typical atheromatous plaque (Levene, 1956b).

The significance of these lesions was not known. Some, like Jores (1903), Bork (1926), Wolkoff (1929), McMeans (1915), and Minkowski (1947) considered all elastic splitting to be the basis for future atheroma. I must say, however, considering that in the coronary artery there are two tensile proteins-elastin and collagen, the latter comprising a large part of the media-it seemed that the internal elastic lamina lesion, which was visible, most likely pointed to an underlying weakness in the collagen of the media, which was itself invisible. But there was no way of proving this at the time. In those days the great Leeds biophysicist, Astbury, was spreading the notion that the fibrous proteins in biology were 'biopolymers' and that, like nylon, they too needed chemically stable cross-links to function. I was very impressed by his clarity and his enthusiasm, which he radiated in the Mather Lecture he delivered in London in 1952 (Astbury, 1953).

Eventually, 14 years later, when I had done most of my work on lathyrism in Boston and in Oxford, I found myself obliged to write a long review of the subject (Levene, 1973). It is a depressing affair parading one's errors in front of one's eyes, trying to reconcile opposing views and not to make too many enemies while still grasping the various nettles which a review invites. The facts were clear: the enzyme that formed the cross-links in elastin and in collagen was the same lysyl oxidase. It required copper as an essential cofactor, so that in copperdeficient swine or chicks aortic rupture occurred because the fibrous proteins responsible for aortic strength, collagen and elastin, were poorly crosslinked and so could not withstand the pressure of the blood.

At this point it might help to illustrate the role of collagen in the developing aorta, even if only in the chick embryo aorta. In Oxford I became interested in the role of aortic collagen. I found that with increasing age the chick embryo developed more collagen on a dry weight basis in its aorta. Moreover, by measuring the breaking strength of the aorta there seemed to be a close relationship between the collagen content at various ages and the tensile strength. If, however, cross-link formation was prevented but collagen synthesis still permitted (this is done by injecting BAPN into the eggs) it was evident that lathyritic aortas which had the same collagen content as the normal controls possessed no strength whatever, since their collagen and elastin was poorly cross-linked or not cross-linked at all. While re- 


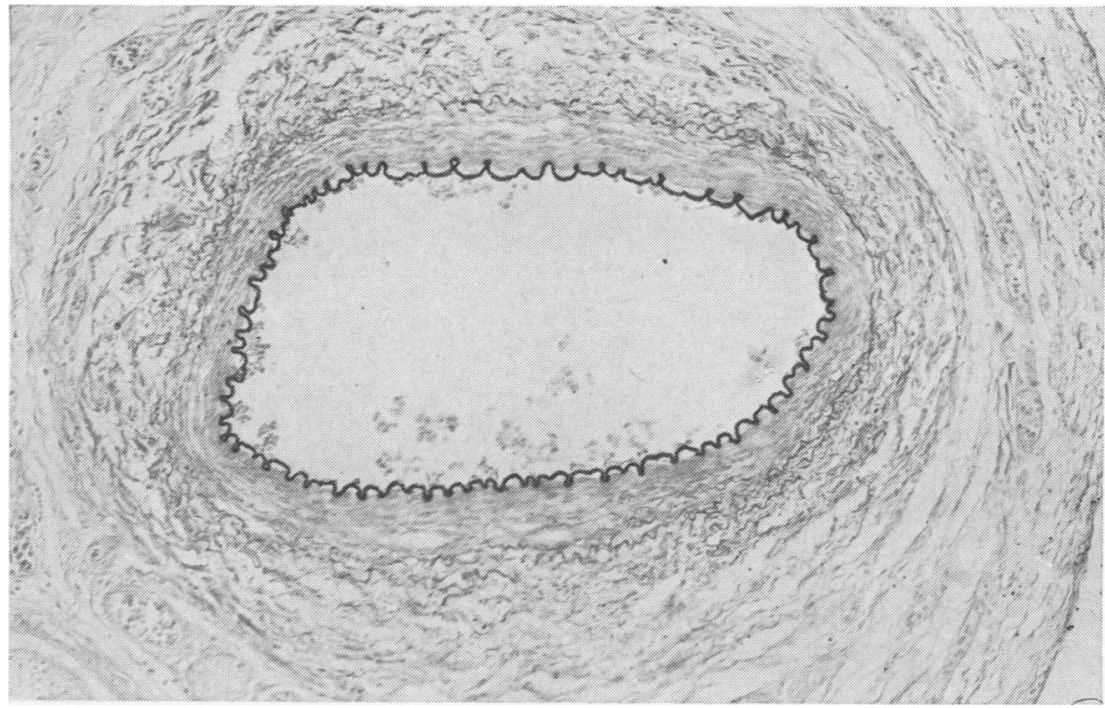

Fig. 2 Coronary artery of infant showing perfect internal elastic lamina (haematoxylin and eosin $\times 75$ ). (Figs $1-5$ reproduced by kind permission of the Editor, Journal of Pathology)

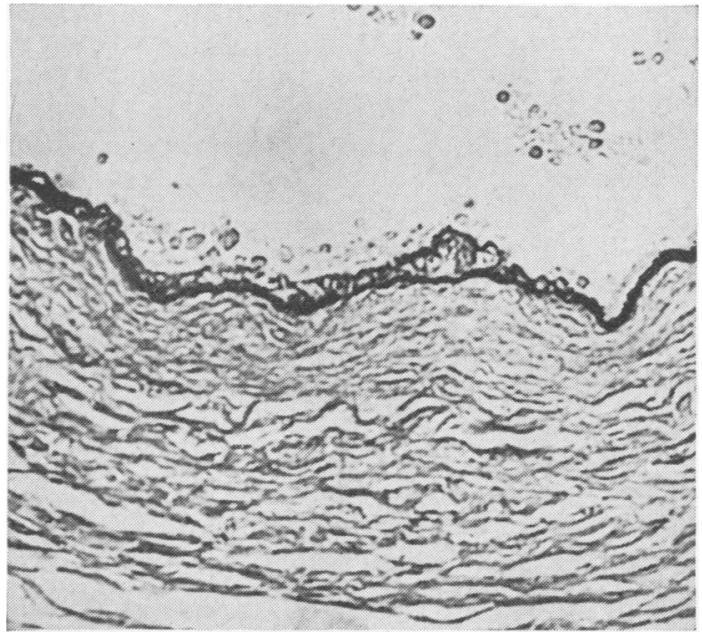

Fig. 3 Coronary artery of infant showing earliest type of elastic lesion. (Haematoxylin and eosin $\times 206$ )

viewing the subject of lathyrism the possibility emerged-particularly from the work of two formidable scientists, Blaschko, the Oxford pharmacologist, and Yasunobu, the enzymologist-that lysyl oxidase was in fact a diamine oxidase and might also require pyridoxal as a cofactor in addition to copper. This possibility was reinforced by the study of Rinehart and Greenberg (1949) who claimed to have produced atherosclerosis in monkeys chronically deficient in vitamin B6.

Sheer ignorance would seem on occasion to be a

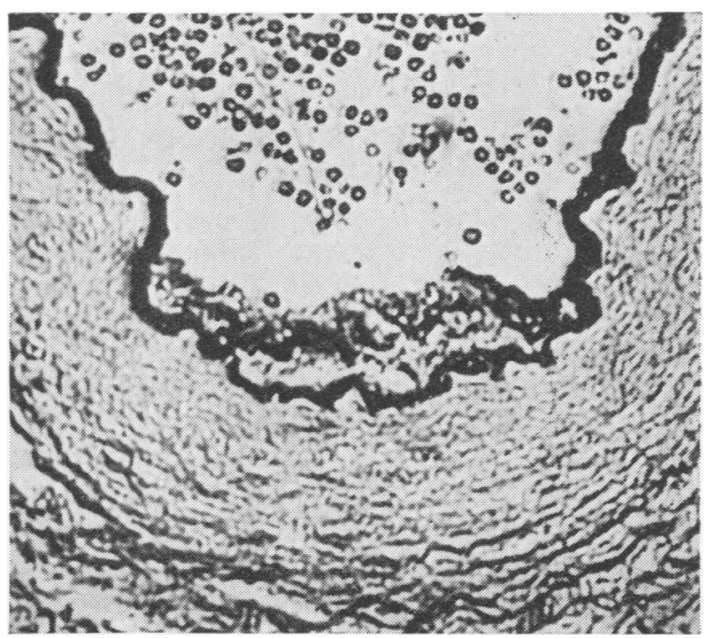

Fig. 4 Coronary artery of infant showing early elastic lesion with early intimal thickening. (Haematoxylin and $\operatorname{eosin} \times 206)$

positive endowment. My research student, now $\mathrm{Dr}$ Murray, and I had not appreciated the difficulties this enzyme would cause and it took us a number of years to provide all but the final proof that lysyl oxidase requires B6 as well as copper as cofactors (Murray, 1977). Our evidence, briefly, is as follows: Radioactively-labelled pyridoxal was unavailable, so it was essential to see whether the injection of ${ }^{3} \mathrm{H}$-pyridoxine into the chick embryo resulted in its conversion into the aldehyde form. We found that 


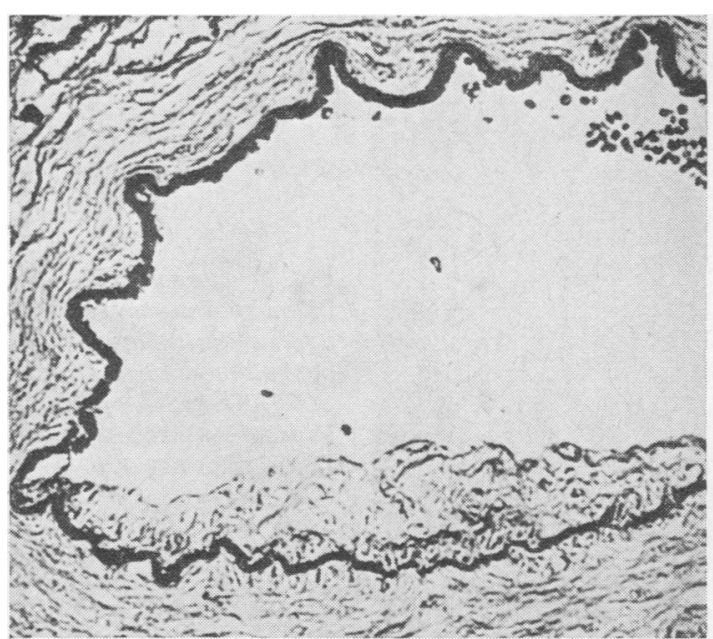

Fig. 5 Coronary artery of infant showing localised stretching of elastica with overlying fibrous intimal plaque. (Haematoxylin and eosin $\times 150$ )

an appreciable amount of conversion into pyridoxal did occur.

Purification of the enzyme presented great problems. To my knowledge only three people in the world were working on it at the time-it is a difficult enzyme. Eventually Murray obtained a more than 9000-fold purification of the enzyme, which was homogeneous on SDS disc-gel electrophoresis and weighed approximately 60000 daltons. Finally he showed that if he chromatographed this pure preparation of the enzyme (which had been isolated from the cartilage of chick embryos previously injected with ${ }^{3} \mathrm{H}$-pyridoxine) the peak of the active enzyme cochromatographed with the peak of ${ }^{3} \mathrm{H}$-pyridoxal (Murray and Levene, 1977). We were never able to isolate the enzyme-pyridoxal complex. Perhaps the Schiff base is too labile. Later, with Fraser, of the Dunn Nutrition Laboratory, we showed that B6-deficient chicks developed severe lesions of their long bone epiphyseal cartilages and a distinct though indefinable morphological change in the aorta. Both organs were found to have a greatly reduced content of lysyl oxidase. However, when $150 \mu \mathrm{g}$ of vitamin B6 was administered 14 hours before sacrifice the levels of lysyl oxidase rose during those 14 hours to well above the normal values (Murray et al., 1978). The evidence that B6 is an essential cofactor for the cross-linking of collagen and elastin seems very strong to me.

\section{Hypothesis}

Where does this leave us vis-a-vis atherosclerosis?
I will tell you about our hypothesis (Levene and Murray, 1977) to explain those lesions of the internal elastic lamina found in the coronary arteries of children at birth. We suggest (see Table) that the

\section{Table Hypothesis on the pathogenesis of atheroma}

(1) Focal internal elastic lamina damage at birth comprises earliest visible lesion in coronary atheroma

(2) Cause unknown

(3) Cross-linking of elastin and collagen essential for proper function

(4) Cross-linking occurs via lysyl oxidase, a copper-dependent enzyme

(5) Vitamin B6 is a second essential cofactor for lysyl oxidase

(6) Pregnancy induces maternal and fetal deficiency of vitamin B6

(7) Fetal vitamin B6 deficiency may thus permit incomplete crosslinking - for example, focal damage to internal elastic lamina

(8) Prophylactic increase in vitamin B6 intake during pregnancy is therefore proposed

focal lesions of the internal elastic lamina in the coronary arteries of children at birth are due to faulty cross-linking of the elastin and, of course, of the underlying collagen in the media of these arteries, and that this faulty cross-linking is due to a deficiency of an essential cofactor, vitamin B6. Lumeng et al. (1976) have established that most pregnant women taking only the $2 \mathrm{mg}$ of vitamin B6 supplement daily advised by the FAO suffer from a functional deficiency. Measurements have been made by SGOT assays, but in 1976 these workers made direct pyridoxal 5'-phosphate measurements on the plasma of the mother and on the cord plasma of the child. It now seems clear that $2 \mathrm{mg}$ daily is insufficient.This multi-disciplinary group has recommended a daily minimum intake during pregnancy of $4 \mathrm{mg}$. Some of you may be surprised that deficiency of such a ubiquitous cofactor as pyridoxal does not kill or severely maim the child but apparently only selectively affects cross-links. Let me reassure you that this does happen. For example, Menkes's kinky hair syndrome (Menkes et al., 1962) is due to a failure of normal copper absorption from the small bowel. Four copper-requiring enzymes are affectedcytochrome oxidase, lysyl oxidase, the enzyme responsible for disulfide bonding in the keratin of the hair, and tyrosinase. Red cell formation, however, which also requires copper, is untouched. There is no anaemia because there is a selective sparing, and so an actual human model already exists.

\section{SUGGESTED SEQUENCE OF EVENTS}

If these focal lesions of the internal elastic lamina are accepted as the first visible manifestation of atherosclerosis, what then? We have no idea of the primary cause-is it intrauterine hypoxia, infection, a sudden rise of blood pressure? What factors decide their localisation-are these inherent in the structure of the blood vessel? No answers exist. But I would like 
to suggest that each focus represents a nidus in the internal elastic lamina and in the collagen of the underlying media on which plaques later develop. I would not claim that mural thrombosis is the only cause of plaque thickening, but when I tell you that in the 98 hearts I examined I found superficial fibrinous encrustations in two of the stillborn infants as well as in many of the others, and these two thrombi were covered by endothelium, you will perhaps forgive me for believing that the deposition and incorporation of fibrin from the blood is responsible, as Duguid has claimed, for at least some of the progressive intimal thickening.

In recent years the work of Ross and his colleagues (Ross, 1973) in Seattle on the role of the medial smooth muscle cell in contributing to the formation of the intimal plaque has attracted much welldeserved attention. More recently he (Harker et al., 1976) has married the smooth muscle cell to the blood platelet and provided evidence that the platelet, on adhering to the intimal wall, releases a factor which is mitogenic for the smooth muscle cell and is also chemotactic, luring it into the intima where it then produces collagen. The evidence stems from his study in vitro of cultured arterial smooth muscle cells. In repeating aspects of his work Barnes and I confirmed that cultured smooth muscle cells (which grow in a very characteristic manner in vitro in hills and valleys, being non-contact inhibited, and which look so different from fibroblasts or from aortic endothelium) do indeed synthesise collagen. In fact, we found both type I and type III collagen as well as elastin (Barnes et al., 1976).

Is this then the whole story? The answer must be no, because we then proceeded to look at aortic endothelium in culture. This too grows in a characteristic but contact-inhibited manner. We managed to show the presence of silver lines in these cells in culture and also that they produced two of the enzymes specific to collagen synthesis-prolyl hydroxylase and lysyl oxidase-as well as the product of these catalysts, collagen (Levene and Heslop, 1977). So one possible conclusion must be that endothelium may also contribute towards the collagen content of the plaque. This was a possibility that Crawford and I considered in our 1952 study of the mode of organisation of aortic mural thrombi (Crawford and Levene, 1952). Those familiar with the monograph on endothelium by Altschul (1954) will know that this cell has often been considered to possess multipotential capacity.

One may question whether what we call an arterial smooth muscle cell may not fundamentally be a fibroblast adapted to a special environment, rather like the myofibroblast described by Majno et al. (1971) in the healing wound.

\section{Possibilities for affecting development of atheroma}

Duguid (1976), while offering a glimmer of hope that we may in time learn to control fibrin formation, is nevertheless slightly pessimistic about our chances of affecting the course of atherosclerosis. He notes that it is a product of ageing and quotes Aschoff that 'there is no remedy for old age'. I have always had the deepest respect and affection for my old chief, but if I agreed with him in this view I would be treating him with less respect than he deserves.

If one is to believe one's own results the logic of the B6 story impels me to a express a slightly more optimistic outlook. There are two things to be done which I believe may prove helpful. Firstly, it should be possible by feeding pregnant mothers with a minimum daily supplement of $4 \mathrm{mg}$ of vitamin B6 to ensure that cross-links develop and thus, perhaps, avoid any sequelae. Secondly, it should be possible to retard or to prevent the development of a sclerotic coronary artery if its aetiology has been a thrombotic episode. Judkins, the American cardiologist, maintained at the recent two-day symposium of the Cardiothoracic Institute that angina pectoris, often the earliest warning of coronary disease, does not usually occur until three-quarters of the lumen has been obstructed. There is no non-invasive way of diagnosing this beforehand. What a remarkably depressing comment! The occluding thrombus organises in the usual way to produce a scar which eventually narrows the lumen, and scarring, once laid down, is irreversible.

I suggest, on the basis of our earlier silicosis work (Levene et al., 1968), that it should be possible to prevent the organisation of the thrombus into a fibrous scar by attacking the eventual synthesis of collagen at the most amenable point and so allow the blood stream to rebore the lumen. This silicosis work had been designed to see whether fibrosis, generally considered an inexorable process not amenable to therapy, could be slowed down therapeutically or even halted. Pulmonary silicosis was produced in rats experimentally and resulted in severe progressive pulmonary fibrosis. Treatment of these animals with BAPN, the lathyrus factor, indicated that it was possible to inhibit the degree of fibrosis by over $50 \%$ without affecting the animals' body weight. The obvious conclusions were that fibrosis need no longer be regarded as the inevitable result of particular pathological processes and that it would be useful to look for sites in the pathway of collagen biosynthesis which might prove amenable to a therapeutic attack on fibrosis.

Finally, I should like to thank the organisers, particularly the President of the Royal College of Pathology, Sir Robert Williams, and the members of 
the committee for having offered me this great distinction today. I obviously did not know Kettle, but I do know some who did. Duguid once told me that Kettle, with whom he worked, loved pathology and had the knack of making it 'fun' for those who worked with him. Many aspects of what I have just spoken of have provided me with great pleasure, and for this I would like to pay tribute to my own teachers-Crawford, who first 'switched me on'; Duguid, of whom I have spoken; Gross in Boston, a stimulating and inspiring scientist and teacher; and Bauer, professor of medicine at Harvard, who believed that basic science should march in tandem with clinical work-a great gardener of men. Lastly, I would like to mention Florey, in whose laboratory one felt: Here was history in the making. McManus, the distinguished scholar, pathologist, and histochemist, once told me that modesty was no virtuewe all, he said, had very good reasons for being modest, being, in research terms, pygmies on the shoulders of giants. He also expressed the opinion that truth was not just 'a rather nice notion' but that one of its great strengths lay in the fact that it actually worked. I hope that I will not have led anyone too far astray today. I thank you.

\section{References}

Adami, J. G. (1909). The nature of the arteriosclerotic process. American Journal of Medical Science, 138, 485-504.

Altschul, R. (1954). Endothelium: Its Development, Morphology, Function and Pathology. Macmillan, New York.

Anitschkow, N. (1913). Über die Veränderungen der Kaninchenaorta bei experimenteller Cholesterinsteatose. Beiträge zur pathologischen Anatomie und zur allgemeinen Pathologie, 56, 379-404.

Astbury, W. T. (1953). The great adventure of fibre structure. (Mather Lecture, 1952.) Journal of the Textile Institute, 44, 81-97.

Barnes, M. J., Morton, L. F., and Levene, C. I. (1976). Synthesis of collagens types I and III by pig medial smooth muscle cells in culture. Biochemical and Biophysical Research Communications, 70, 339-347.

Beitzke, H. (1928). Zur Entstehung der Atherosklerose. Virchows Archiv für pathologische Anatomie und Physiologie und für klinische Medizin, 267, 625-647.

Benditt, E. P., and Benditt, J. M. (1973). Evidence for a monoclonal origin of human atherosclerotic plaques. Proceedings of the National Academy of Sciences of the United States of America, 70, 1753-1756.

Bork, K. (1926). Ueber Kranzadersklerose. Virchows Archiv für pathologische Anatomie und Physiologie und für klinische Medizin, 262, 646-657.

Crawford, T., and Crawford, M. D. (1967). Prevalence and pathological changes of ischaemic heart-disease in a hard-water and in a soft-water area. Lancet, 1, 229232.
Crawford, T., and Levene, C. I. (1952). The incorporation of fibrin in the aortic intima. Journal of Pathology and Bacteriology, 64, 523-528.

Crawford, T., and Levene, C. I. (1953). Medial thinning in atheroma. Journal of Pathology and Bacteriology, 66, 19-23.

Duguid, J. B. (1926). Atheroma of the aorta. Journal of Pathology and Bacteriology, 29, 371-387.

Duguid, J. B. (1946). Thrombosis as a factor in the pathogenesis of coronary atherosclerosis. Journal of Pathology and Bacteriology, 58, 207-212.

Duguid, J. B. (1976). The Dynamics of Atherosclerosis. Aberdeen University Press, Aberdeen.

Faber, A. (1912). Die Arteriosklerose; ihre pathologische Anatomie; ihre Pathogenese und Aetiologie. Fischer, Jena.

Geiringer, E. (1951). Intimal vascularisation and atherosclerosis. Journal of Pathology and Bacteriology, 63, 201-211.

Harker, L. A., Ross, R., and Glomset, J. (1976). Role of the platelet in atherogenesis. Annals of the New York Academy of Sciences, 275, 321-329.

Harrison, C. V. (1933). Experimental arterial disease produced by cholesterol and vitamin D. Journal of Pathology and Bacteriology, 36, 447-453.

Harrison, C. V. (1948). Experimental pulmonary arteriosclerosis. Journal of Pathology and Bacteriology, 60, 289-293.

Heard, B. E. (1949). Mural thrombosis in the renal artery and its relation to atherosclerosis. Journal of Pathology and Bacteriology, 61, 635-637.

Jores, L. (1903). Wesen und Entwicklung der Arteriosklerose. Bergmann, Wiesbaden.

Levene, C. I. (1956a). The early lesions of atheroma in the coronary arteries. Journal of Pathology and Bacteriology, 72, 79-82.

Levene, C. I. (1956b). The pathogenesis of atheroma of the coronary arteries. Journal of Pathology and Bacteriology, 72, 83-86.

Levene, C. I. (1973). Lathyrism. In Molecular Pathology of Connective Tissues, edited by R. Pérez-Tamayo and M. Rojkind, pp. 175-228. Dekker, New York.

Levene, C. I. Bye, I. Saffiotti, U. (1968). The effect of B-aminopropionitrile on silicotic pulmonary fibrosis in the rat. British Journal of Experimental Pathology, 49, 152-159.

Levene, C. I., and Heslop, J. (1977). The synthesis of collagen by cultured pig aortic endothelium and its possible role in the pathogenesis of the fibrous atherosclerotic plaque. Journal of Molecular Medicine, 2, 145 151.

Levene, C. I., and Murray, J. C. (1977). The aetiological role of maternal vitamin-B6 deficiency in the development of atherosclerosis. Lancet, 1, 628-630.

Lumeng, L., Cleary, R. E., Wagner, R., Pao-Lo Yu, and Ting-Kai Li (1976). Adequacy of vitamin B6 supplementation during pregnancy: a prospective study. American Journal of Clinical Nutrition, 29, 1376-1383.

McMeans, J. W. (1915). The splitting of the elastic fibers in arteries. Journal of Medical Research, 33, 377-390.

Magarey, F. R. (1949). On the mode of formation of Lambl's excrescences and their relation to chronic 
thickening of the mitral valve. Journal of Pathology and Bacteriology, 61, 203-208.

Majno, G., Gabbiani, G., Hirschel, B. J., Ryan, G. B., and Statkor, P. R. (1971). Contraction of granulation tissue in vitro: similarity to smooth muscle. Science, 173, 548-550.

Marchand, F. (1904). Úber Arteriosklerose. Verhandlungen des Kongresses für innere Medizin, 21, 23-59.

Menkes, J. H., Alter, M., Steigleder, G. K., Weakley, D. R., and Sung, J. H. (1962). A sex-linked recessive disorder with retardation of growth, peculiar hair and focal cerebral and cerebellar degeneration. Pediatrics, 29, 764-779.

Minkowski, W. L. (1947). The coronary arteries of infants. American Journal of Medical Science, 214, 623629.

Mole, R. H. (1948). Fibrinolysin and the fluidity of the blood post-mortem. Journal of Pathology and Bacteriology, 60, 413-427.

Murray, J. C. (1977). Evidence for the role of pyridoxal phosphate as a cofactor of 'lysyl oxidase'. Ph.D. Thesis, Cambridge University.

Murray, J. C., and Levene, C. I. (1977). Evidence for the role of vitamin B-6 as a cofactor of lysyl oxidase. Biochemical Journal, 167, 463-467.

Murray, J. C., Fraser, D. F., and Levene, C. I. (1978). The effect of pyridoxine deficiency on lysyl oxidase activity in the chick. Journal of Experimental and Molecular Pathology, in press.

Rinehart, J. F., and Greenberg, L. D. (1949). Arterio- sclerotic lesions in pyridoxine-deficient monkeys. American Journal of Pathology, 25, 481-492.

Rokitansky, C. (1852). A Manual of Pathological Anatomy, vol. 4, translated by G. E. Day, p. 272. Sydenham Society, London.

Ross, R. (1973). The smooth muscle cell in connective tissue metabolism and atherosclerosis. In Biology of Fibroblast: Fourth Sigrid Jusélius Foundation Symposium, Turku, Finland, Aug. 1972, edited by E. Kulonen and J. Pikkarainen, pp. 627-636. Academic Press, London and New York.

Thoma, R. (1896). Textbook of General Pathology and Pathological Anatomy, translated by A. Bruce. A. and C. Black, London.

Virchow, R. (1856). Der atheromatöse Prozess der Arterien. Wiener medizinische Wochenschrift, 6, 809825.

Winternitz, M. C., Thomas, R. M., and LeCompte, P. M. (1938). The Biology of Arteriosclerosis, p. 103. Thomas, Springfield, Illinois.

Wolkoff, K. (1929). Über die Atherosklerose der Coronarterien des Herzens. Beiträge zur pathologischen Anatomie und zur allgemeinen Pathologie, 82, 555-596.

Yudkin, J., and Roddy, J. (1964). Levels of dietary sucrose in patients with occlusive atherosclerotic disease. Lancet, 2, 6-8.

Ziegler, E. (1896-97). A Textbook of Special Pathological Anatomy, translated and edited from the 8th German edition by D. MacAllister and H. W. Cattell. Macmillan, New York. 